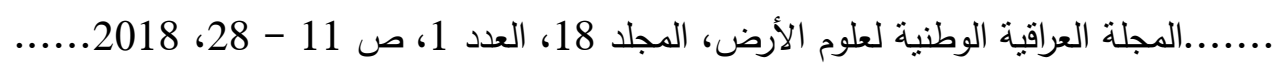

استخراج البصمة الطيفية للمقحمات البكمتايتية وتحديد انتشارها في المرئيات الفضائية

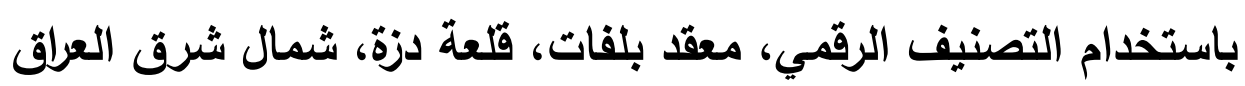

\author{
نها به ز رشيد حمه عزيز \\ شريف ثمود الحامد \\ ريان غازي البنا \\ قسم علوم الأرض

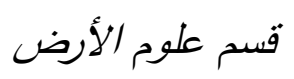 \\ مركز التحسس النائي \\ كلية العلوم \\ كلية العلوم \\ جامعة الموصل مركل \\ جامعة السلبيانية \\ جامعة الموصل \\ (تاريخ الاستلام 2013/4/8 ، تاريخ القبول 2013/6/26 )
}

الملخص

تعد الدقحمات البكمنايتية إحدى المظاهر الجيولوجية المميزة التي تتكثف في الجزء الثمالي الغربي من نطاق درز زاكروس بهيئة مقحمات تقطع وحدات بركانية - رسوبية. لغرض تحديد وجود وانتشار هذه

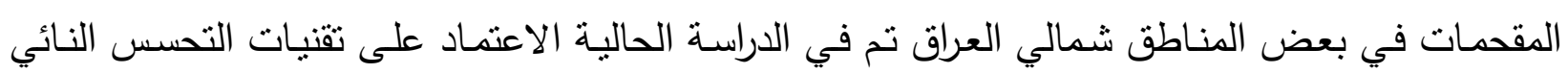

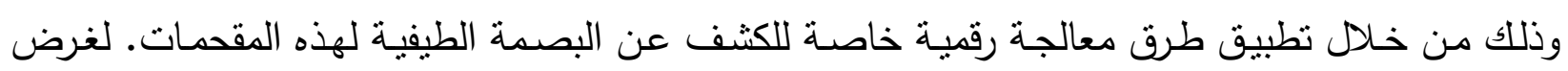

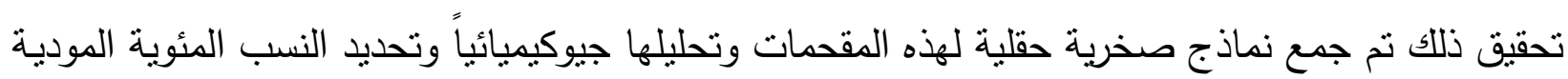

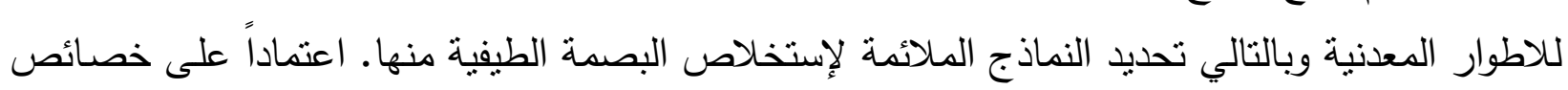

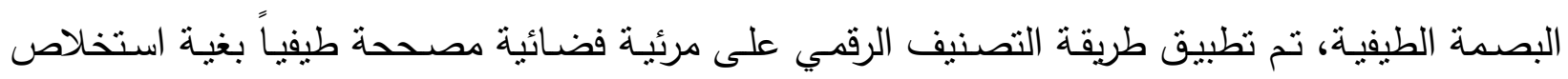

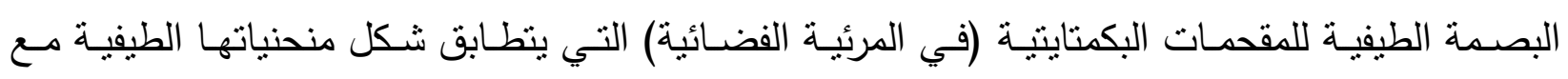

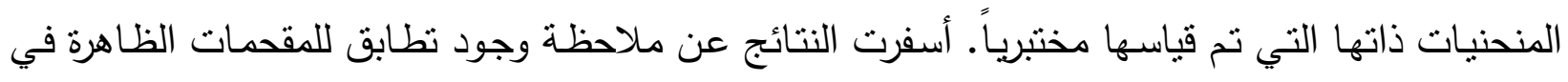

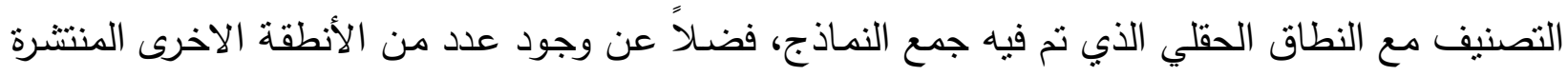

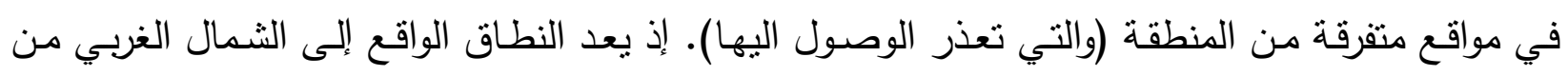

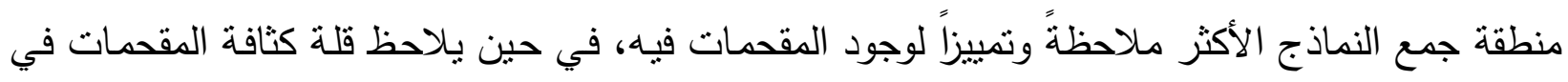

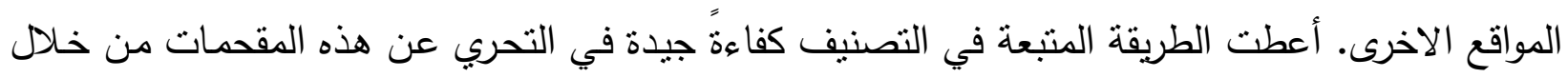

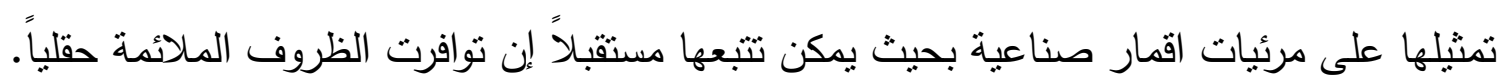

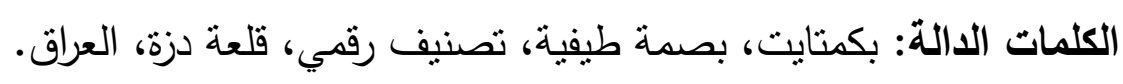

\section{Spectral Signature Extraction of Pegmatite Intrusions and Determine it by Using Supervised Classification, Bulfat Complex, Qala Deza, NE Iraq}


Rayan Gh. Al-Banaa

Remote Sensing Center

University of Mosul
Shareef Th. Al-hamed

Department of Geology

College of Science

University of Mosul
Nabaz R. H. Aziz

Department of Geology

College of Science

University of Sulaymania

\begin{abstract}
Pegmatite intrusions represent one of the distinguished geological features which are exposed in the north western part of Zagros Suture Zone-ZSZ whose forms appear like dikes and its contain of Volcano-Sedimentary units. In order to determine these features in some areas northern Iraq, remote sensing techniques were used by applying selective image processing methods for determining the spectral signature of these intrusions. Lithological samples were collected and analyzed geochemically and specify Mode analysis of minerals phases and consequently determination the suitable samples for spectral extraction. Depending on the extracted spectral, digital classification was applied on the corrected satellite images to extract the compatible spectral signatures between pegmatite intrusions (in satellite images) and pegmatite field samples. The results showed coincident between this two pegmatite and also determine another zones of pegmatite out of studied area. The density of pegmatite is more in the zone which is located northwestern part from samples area and low density in the other area. The research method gave good efficiency in pegmatite investigation by clarifying these features on the satellite images.
\end{abstract}

Keywords: pegmatite, spectral signature, digital classification, Qala Deza, Iraq.

\footnotetext{
المقدمة

البكمتايت عبارة عن صخور نارية غير اعتيادية تتميز بخشونة حبيباتها المعدنية (Schneiderhohn,1961) الثمالي الغربي من نطاق درز زاكروس (Zagros Suture Zone-ZSZ) على شكل قواطع (Dykes) تقطع صخور الجدار (Country Rocks) المنتكة بصخور قنديل المتحولة والتي تتكون من تعاقبات بركانية ورسوبية متأثرة بتحولات إقليمية (Jassim et al., 1982b)، إذ تتألف هذه التعاقبات في منطقة

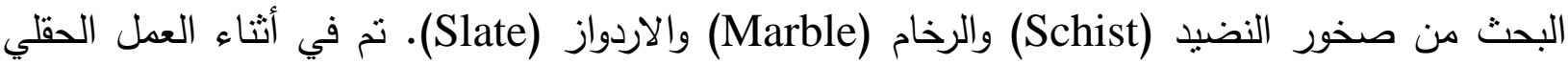
وبعد الاستفسار من سكان القرى المحيطة بمنطقة الدراسة اختبار منطقة محدودة ومؤمنة من ناحية الألغام، إذ اعتمدت النمذجة على الملاحظات الحقلية (التباين في حجم الحبيبات والمحتوى المعدني). فيما يخص التحري عن القواطع الاخرى لصخور البكمنايت في مواقع خارج منطقة الدراسة، فقد كان

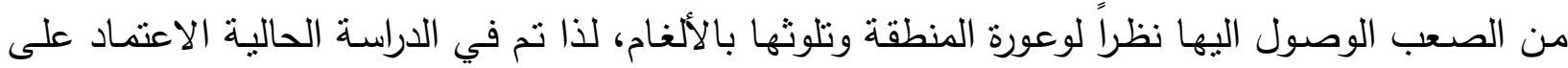


تقنيات التحسس النائي في تحديد امكانية وجود هذه القواطع في تلك المناطق عن طريق البصمة الطيفية

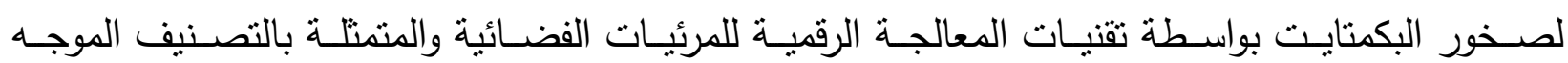
(Supervised classification) إستخراج الخصائص الطيفية (الامتصاص والانعكاس) للمقحمات البكمتايتية في الجزء الثمالي الغربي من فن فئن نطاق درز زاكروس بواسطة جهاز التحليل الطيفي وتحديد انتشارها من خلال اجراء معالجة التصنيف الموجها لألئه وبالتالي تمثيل تلاك المقحمات على مرئية فضائية.

\section{موقع منطقة الاراسة}

تقع منطقة الدراسة في شمال شرق العراق وتحديداً على بعد (74 Km) شمال شرق مدينة السليمانية

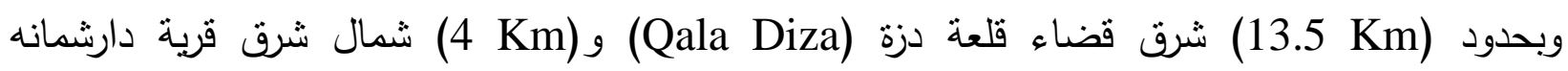

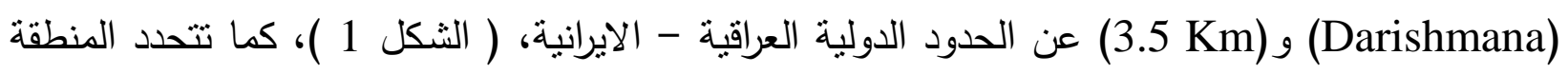

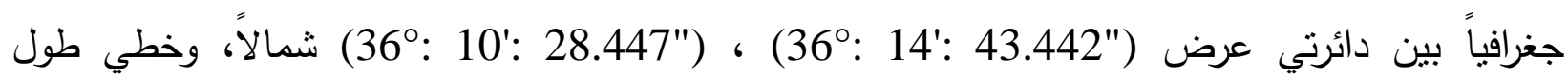

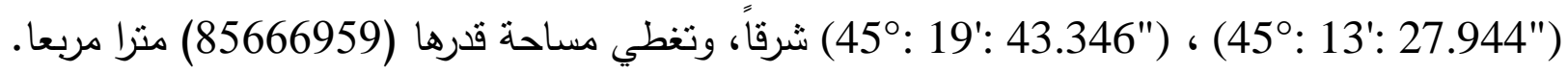
جيولوجياً تتموضع منطقة البحث ضمن معقد بلفات (Bulfat Complex) : التابع لنطاق درز زاكروس وضمن الوحدة الطولية الثانية من نطاق بنجوين - والاش الثانوي (Penjween-Walash Subzone) (الثنكل 2) (Buday and Jassim, 1987) اعتمدت عملية النمذجة على إثنين من السدود القاطعة (قواطع، Dykes) التي تقطع صخور

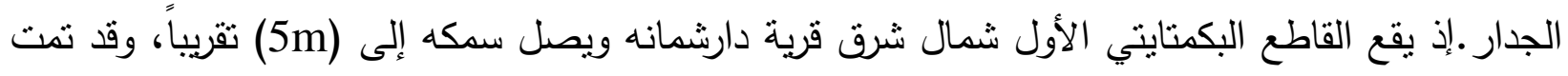

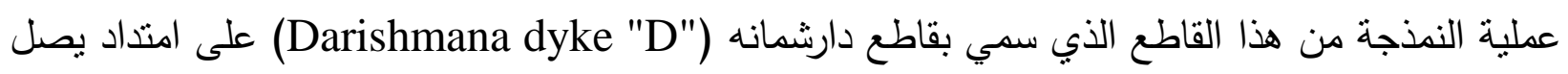

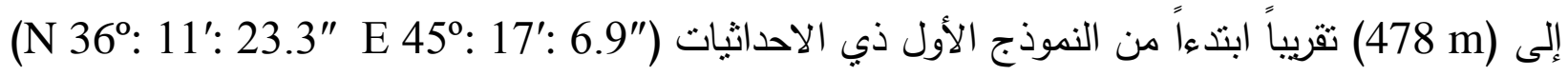
وانتهاءاً بالنموذج الأخير ذي الاحداثيات ( N 36" : 11': 24.2"

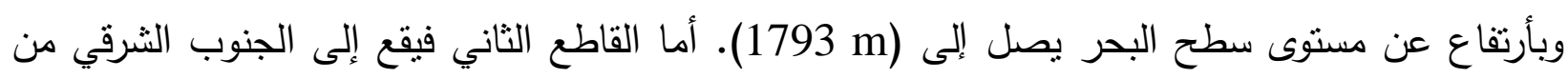
قرية هولثو (Halsho) وسمي بقاطع هولثو (Halsho dyke "H") نسبةً إلى اسم هذه القئل القرية،

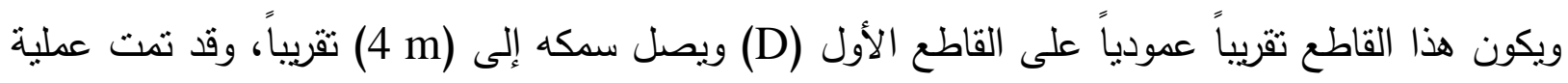

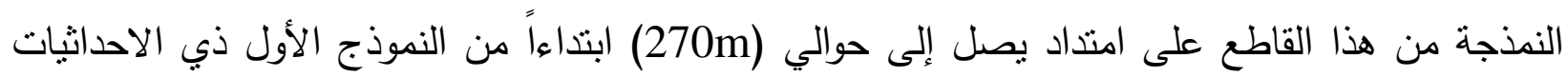

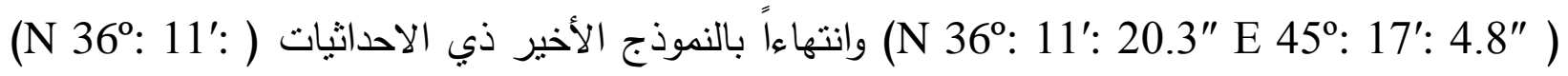

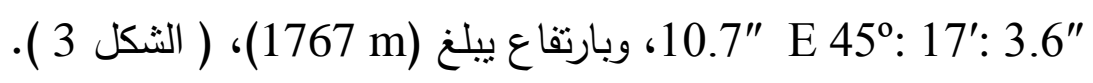




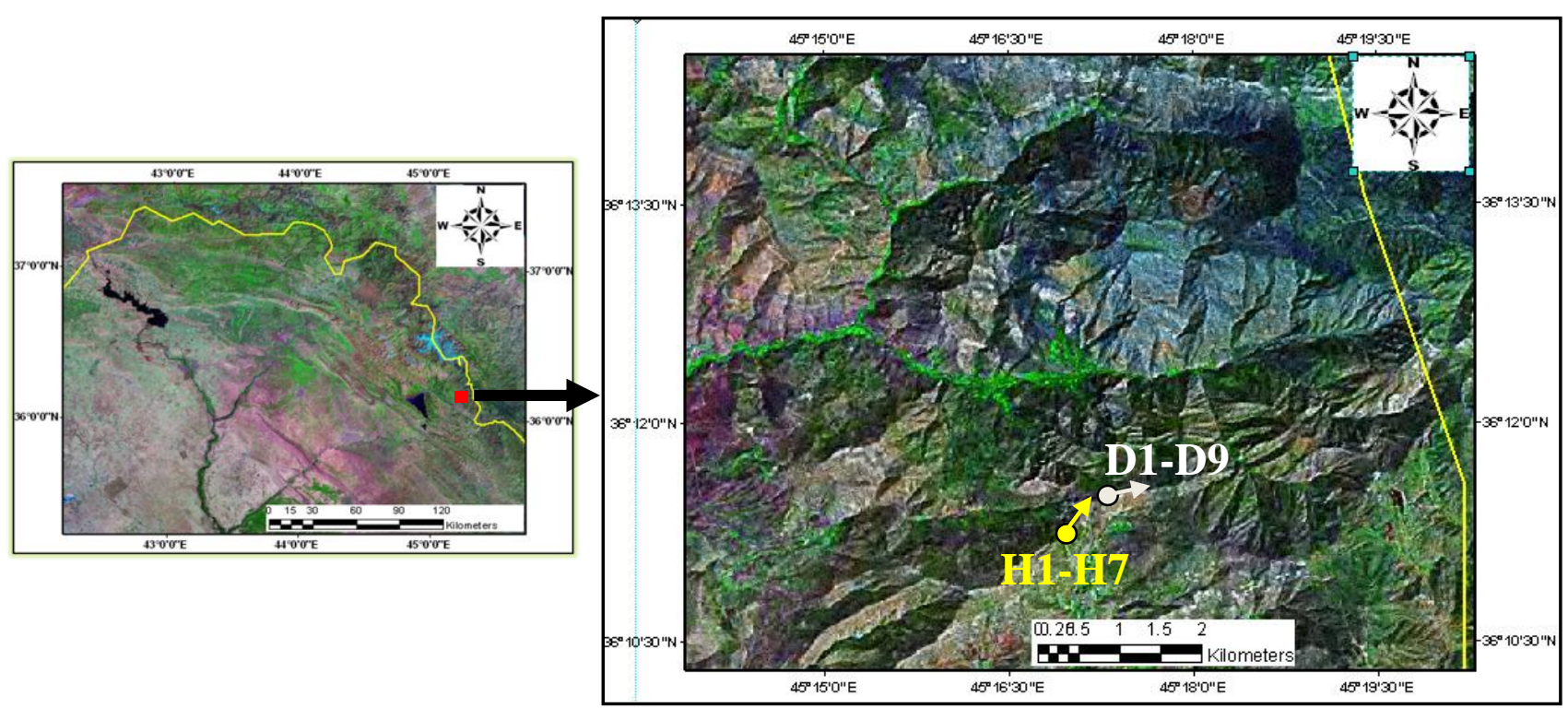

الثكل 1: موقع منطقة الدراسة بالنسبة للعراق موضحاً عليها مواقع جمع النماذج.

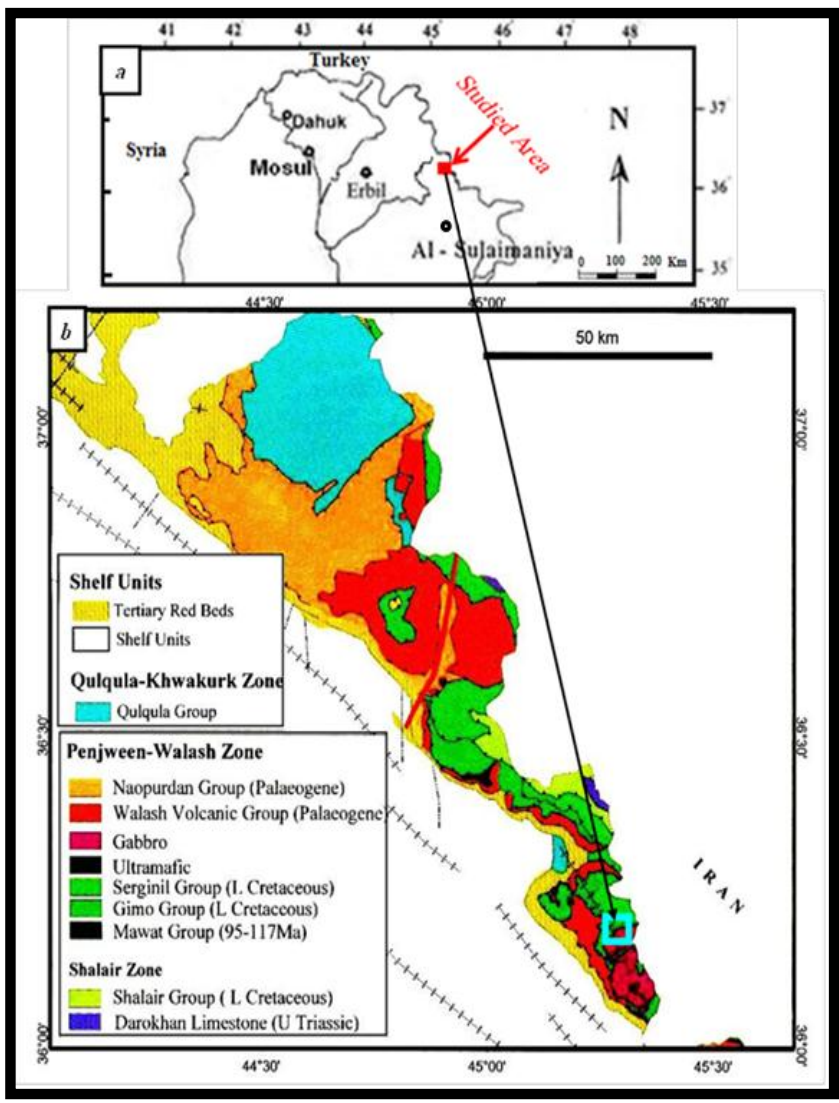

الشكل 2: (a) خربطة لشمال العراق توضح موقع منطقة الدراسة، (b) خربطة جيولوجية للجزء الثمالي الغربي من درز زاكروس (Jassim and Buday, 2006). 


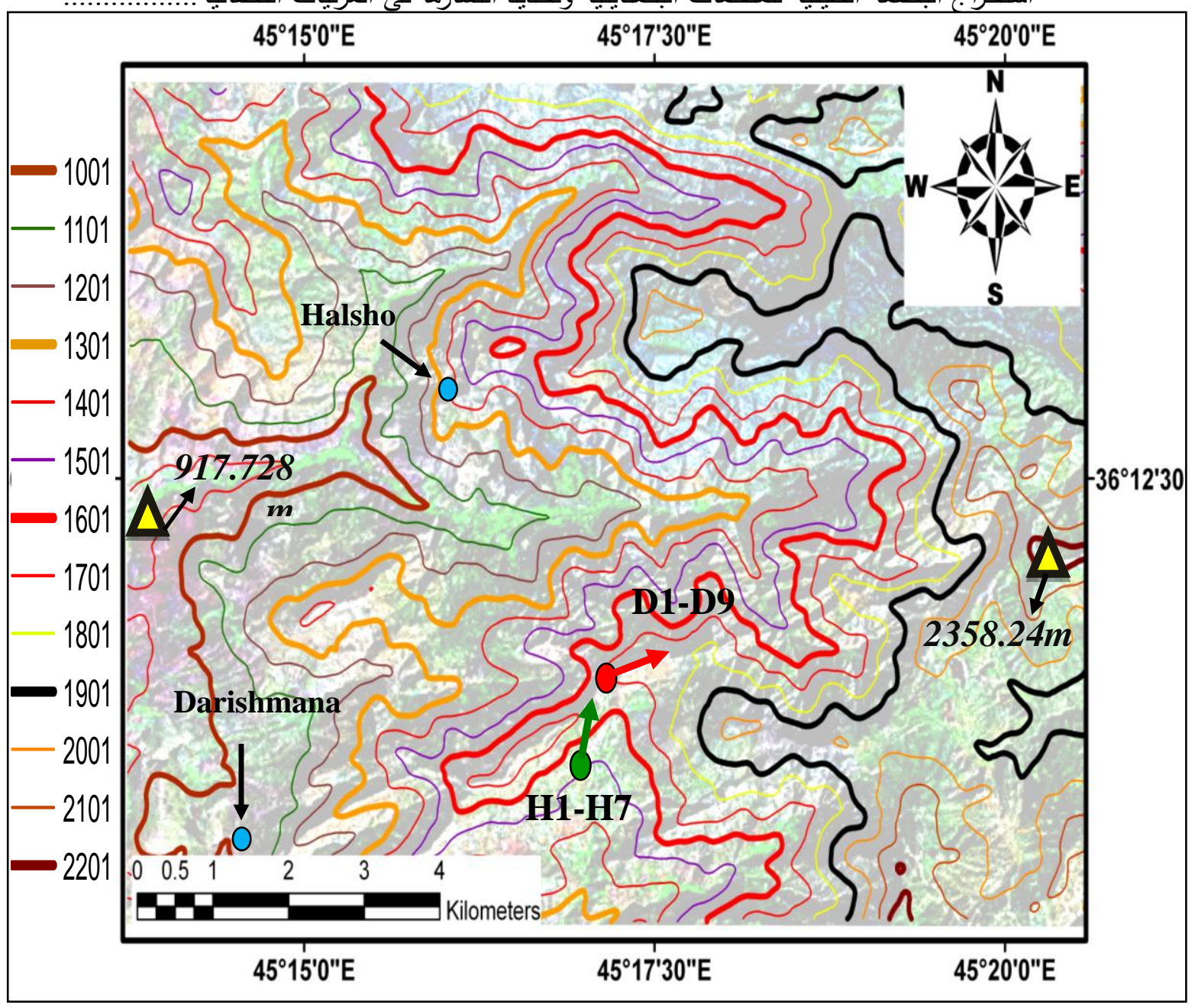

الثكل 3: خارطة كنتورية لمنطقة الدراسة موضحاً عليها مواقع النماذج.

ينكثف معقد بلفات الذي تعد منطقة البحث جزءاً منه داخل العراق عند جبل بلفات بالقرب من قضاء

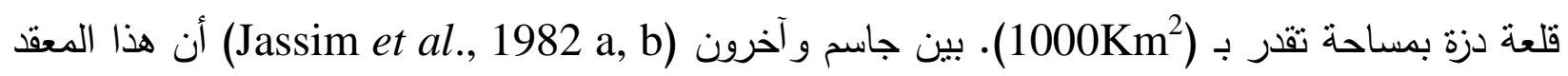
عبارة عن تتابع اوفيولايتي (Ophiolite Sequence) غير كامل يتألف من وحدة بركانية - رسوبية تثير إلى مجموعة بلفات (Bulfat Group) المتمثلة بمجموعة كيمو (Volcano-Sedimentary unit) (Gimo Group)

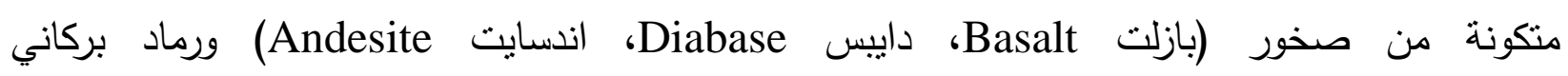
(Volcanic Tuff) منطقة كيمو الواقعة شمال معقد ماوات (Mawat Complex)، إذ تمتد هذه المجموعة إلى معقد بلفات

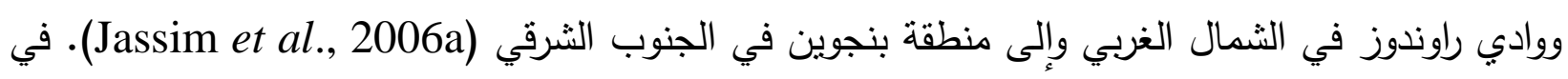

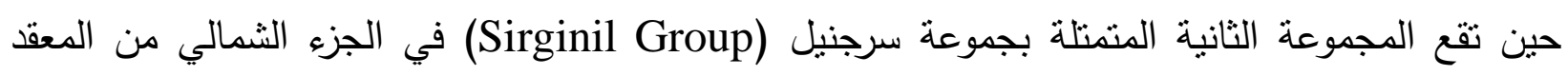

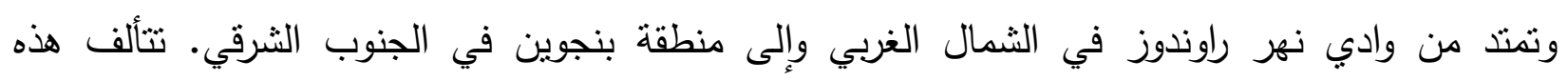

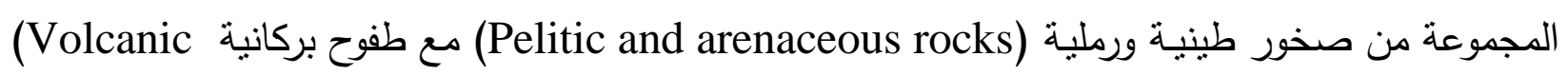


عانت تحولاً اقليمياً وتماسياً (Buday and Suk, 1978) مشكلةً الجزء العلوي من مجموعة بلفات Ophiolite-) (Jassim et al., 2006a) bearing terranes والتي هي عبارة عن ألواح منقولة( Allochthonous sheets)، إذ يمنل المعقد اللوح العلوي المنقول (Upper Allochthon) الذي يعود إلى الألبيان سينوماني (Albian-Cenomenian)، في حين يمنل تتابع والاش - ناوبردان (Walash-Naopurdan) اللوح السفلي المنقول ( Lower) (Allochthon الألواح المنقولة فوق الترسبات الموضعية (Autochthonous deposits) المتمنلة بترسبات الرصيف العربي وصخور الغطاء الرسوبي الثلاثي (Aswad, 1999) ( الثكل 4 ).

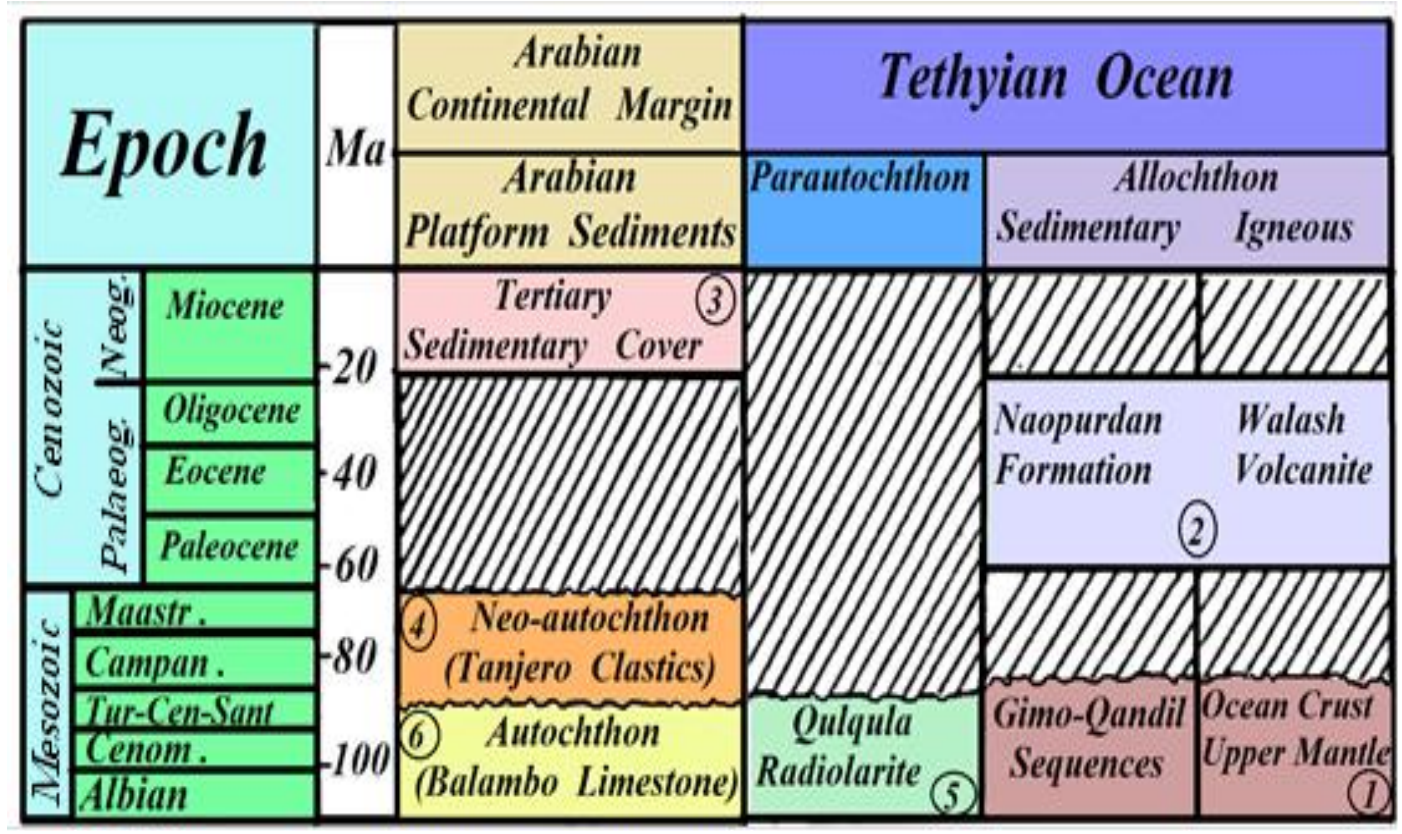

الثكل 4: التطور الطباقي التكتوني لنطاق الزحف الزاكروسي العراقي (Aswad, 1999).

يتكون معقد بلفات بشكل عام من الصخور الجوفية (صخور قاعدية وصخور فوق قاعدية مع وجود صخور متوسطة وحامضية كرانيتية) التي تتألف بصورة رئيسة من مقحمات الكابرو - دايورايت (Gabbro - Diorite) عن عملية التفاضل الصهيري المتأخر (Jassim, et al., 2006b). في حين يحتوي المعقد بالقرب من قرية باوزة (Pauza) (وادي شابان) على صخور فوق قاعدية متمنلة بصخور بريدوتايت (Peridotite) متأثرة بعملية السربنتـة (Serpentinization)، وكذلك يحتوي معقد بلفات في جزئه الشمالي الشرقي على صخور بايروكسين - هوربلند كابرو (Pyroxene-hornblende gabbro) التي تمثل مجمل المنكثفات الصخرية على طول الحدود بين العراق وايران في ذلك الجزء من المعقد، كما وتتتشر صخور الاوليفين كابرو على شكل أجسام صخرية تحتوي على كميات متباينة من معدن الاوليفين، في حين (Olivine Gabbro) تتوزع صخور البكمتايت (Pegmatite) على شكل قواطع خشنة الحبيبات تقطع الصخور الجوفية وصخور 
الجدار الدحيطة (Jassim, et al., 2006b)، وتكون هذه القواطع البكمتايتية ذات سماكات صغيرة من الصعب تحديدها على الخريطة الجيولوجية. يوضح (الثكل 5) الخريطة الجيولوجية لمعقد بلفات.

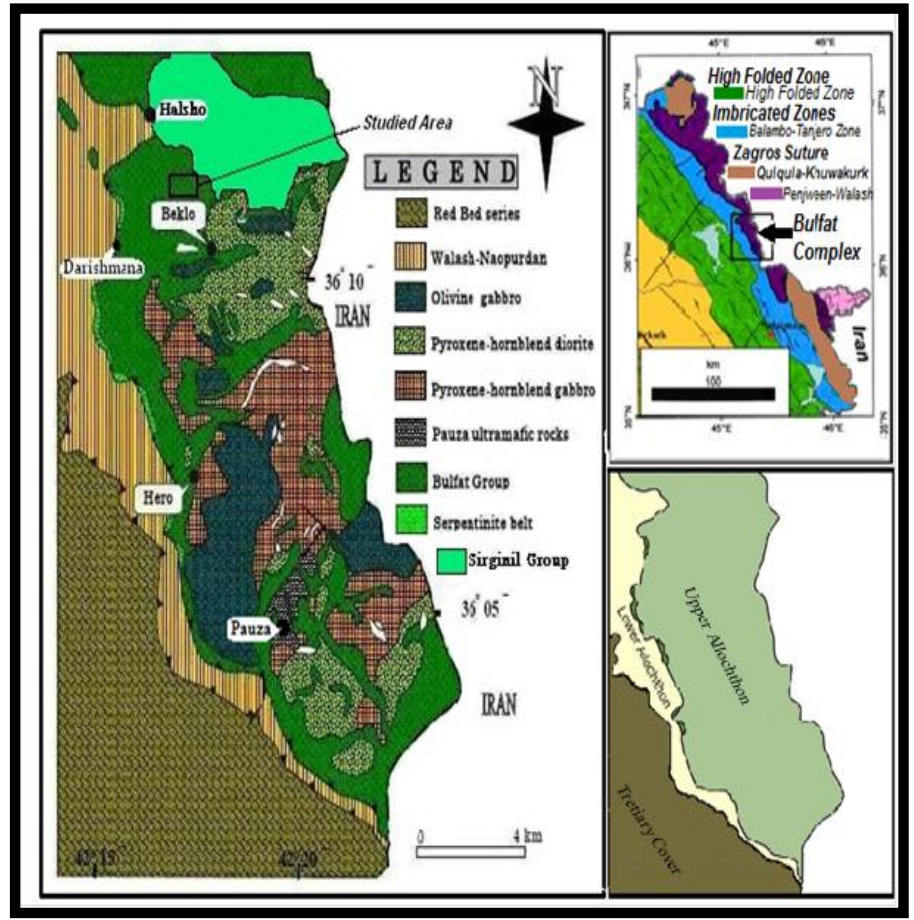

الثكل 5: الخريطة الجيولوجية لمعقد بلفات (Buday and Jassim, 1987).

\section{طريقة العمل}

تم انتخاب (4) نماذج صخرية من بين (38) نموذجاً تعود إلى منطقة البحث، إذ تمثل هذه النماذج النهل

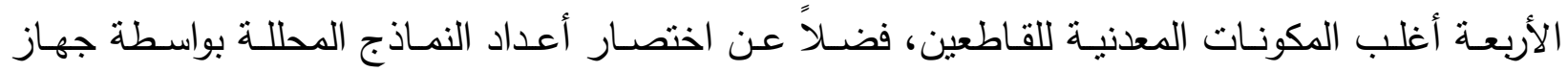
المطياف واختصـار الوقت الـلازم في عمليـة التحليل. تعد النمـاذج المنتخبـة ممنلـة (representative)

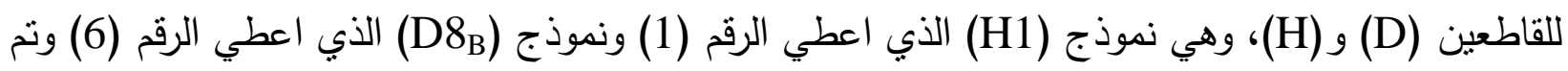

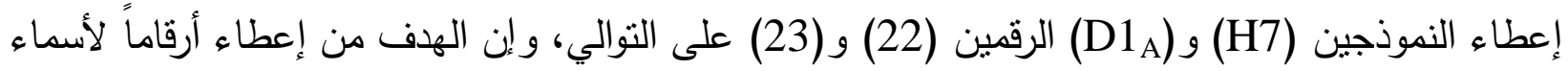

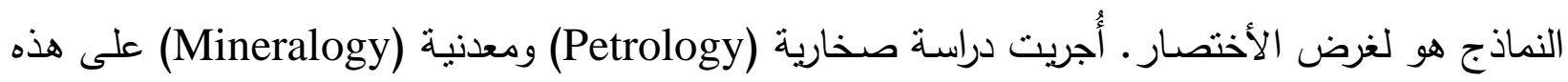
النماذج لتحديد إنتمائها إلى أنواعها الصخرية، إذ تضمنت هذه الدراستة الدراستة تحديد النسب المئوية المودية للأطوار

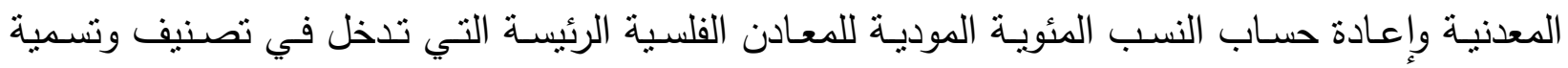
الصخور وهي الكوارتز (Quartz) والفلدسبار القلوي (Alkali-feldspar) والبلاجيوكليس (Plagioclase) (الجدول 1 ) ونم الأعتماد على مخطط (Quartz, Alkali-feldspar, Plagioclase, Feldspathoid) المختصر بـ (Streckeisen, 1976) ( الثكل 6 )، وكانت النسبة المئوية المودية للكوارتز في هذه الصخور لاتتجاوز (5\%) لذاللك لم تؤخذ نسبة الكوارتز بعين الأعتبار أثناء التصنيف، كما لم يتم 
ملاحظة معادن الفلدسبثويد في الصخور تحث البحث. فضلاً على ذلك فقد تم الاستعانة بتقنية (ICP-MS) لإيجاد تراكيز العناصر الرئيسة والأثرية في هذه الصخور (الجدول 2).

الجدول 1: إعادة حساب النسبة المئوية المودية للفلدسبار القلوي (A' (P' ) والبلاجيوكليس (P) وتسمية الصخور تحت البحث.

\begin{tabular}{|c|c|c|c|c|c|c|}
\hline \multirow{2}{*}{$\begin{array}{c}\text { Sam } \\
\text { ples }\end{array}$} & \multirow{2}{*}{$\begin{array}{c}\text { No. } \\
\text { samples }\end{array}$} & \multirow{2}{*}{$\begin{array}{c}\text { Alk-fld. } \\
\text { \% }\end{array}$} & \multirow{2}{*}{ Plg. \% } & \multicolumn{2}{|c|}{\begin{tabular}{c} 
Total Feldspars \\
\multirow{2}{*}{ Rocks }
\end{tabular}} \\
\cline { 5 - 6 } D1 $_{\mathbf{A}}$ & 23 & 59.8 & 23.2 & 72 & 28 & Syenitic pegmatite \\
\hline D8 & 6 & 0.6 & 36.9 & 1.7 & 98.3 & Gabbroic pegmatite \\
\hline H1 & 1 & 75.6 & 13.4 & 85 & 15 & Syenitic pegmatite \\
\hline H7 & 23 & 60.1 & 17.9 & 77 & 23 & Syenitic pegmatite \\
\hline
\end{tabular}

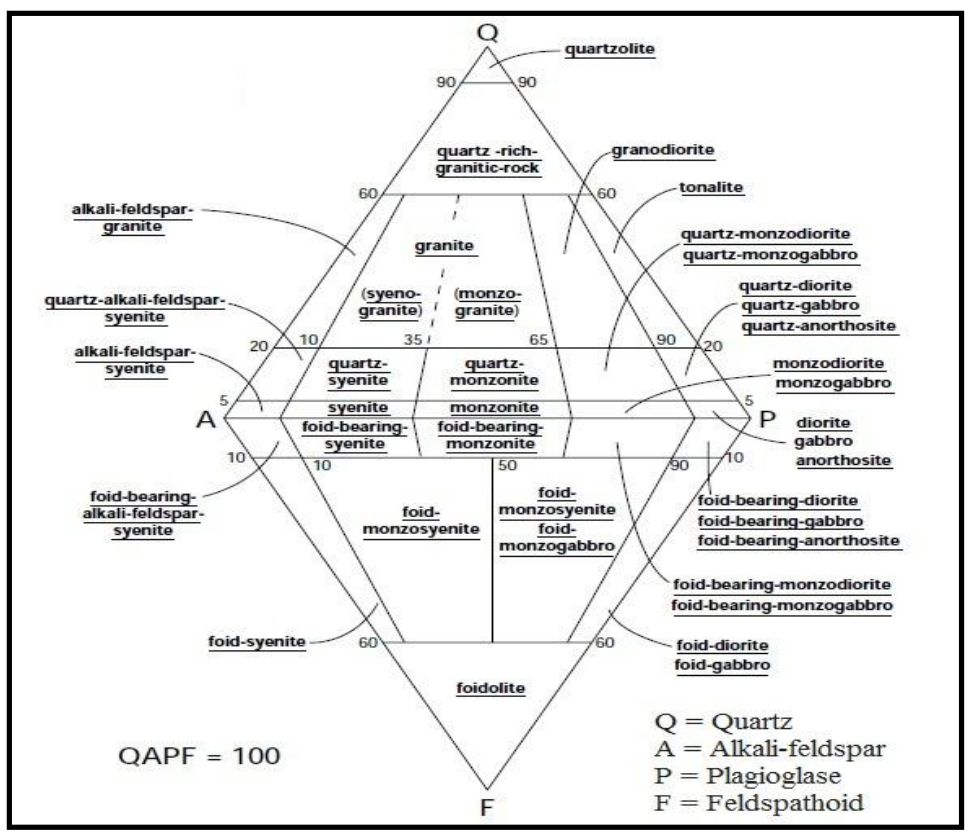

المحتوى المعدني (Streckeisen, 1976). 
الجدول 2: تحاليل العناصر الرئيسة والأثرية بتقنية (ICP- MS).

\begin{tabular}{|c|c|c|c|c|c|}
\hline \multicolumn{2}{|c|}{$\begin{array}{c}\text { Samples } \\
\text { Elements }\end{array}$} & $\mathrm{D1}_{\mathrm{A}}$ & $\mathrm{D8}_{\text {B }}$ & H1 & H7 \\
\hline \multirow{15}{*}{ 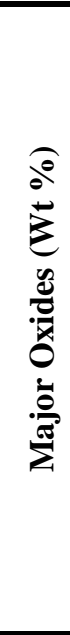 } & $\mathrm{SiO}_{2}$ & 59.890 & 46.909 & 58.334 & 57.522 \\
\hline & $\mathrm{Al}_{2} \mathrm{O}_{3}$ & 16.642 & 13.280 & 21.043 & 18.663 \\
\hline & $\mathrm{FeO}$ & 4.905 & 5.932 & $\begin{array}{l}1.199 \\
\end{array}$ & 1.989 \\
\hline & $\mathrm{Fe}_{2} \mathrm{O}_{3}$ & 1.723 & 3.554 & 0.725 & 2.334 \\
\hline & $\mathrm{MgO}$ & 0.663 & 4.394 & 0.149 & 0.265 \\
\hline & $\mathrm{CaO}$ & 3.861 & 17.683 & 1.273 & 2.043 \\
\hline & $\mathrm{Na}_{2} \mathrm{O}$ & 6.102 & 2.629 & 11.709 & 12.669 \\
\hline & $\mathrm{K}_{2} \mathrm{O}$ & 4.615 & 0.458 & 3.784 & 3.000 \\
\hline & $\mathrm{P}_{2} \mathrm{O}_{5}$ & 0.284 & 1.466 & 0.050 & 0.119 \\
\hline & $\mathrm{TiO}_{2}$ & 0.677 & 1.746 & 0.195 & 0.599 \\
\hline & $\mathrm{MnO}$ & 0.136 & 0.149 & 0.038 & 0.097 \\
\hline & LOI & 0.5 & 1.8 & 1.5 & 0.7 \\
\hline & Total & 100 & 100 & 100 & 100 \\
\hline & Fe total & 5.02 & 7.10 & 1.44 & 3.18 \\
\hline & $M g \#$ & 0.075 & 0.309 & 0.070 & 0.074 \\
\hline \multirow{30}{*}{ 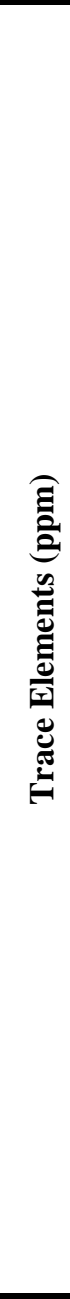 } & $\mathrm{Ni}$ & 3.8 & 16.4 & 1.2 & 0.5 \\
\hline & $\mathrm{Sc}$ & 0.4 & 7.2 & 0.2 & 1.5 \\
\hline & $\mathrm{Cr}$ & - & - & 2 & 2 \\
\hline & Co & 10.5 & 37.9 & 21.9 & 9.1 \\
\hline & $\mathrm{V}$ & 6 & 158 & 1 & - \\
\hline & $\mathrm{Rb}$ & 104.4 & 17.5 & 77.3 & 54.7 \\
\hline & $\mathrm{Pb}$ & 16.13 & 4.62 & 6.29 & 3.55 \\
\hline & $\mathrm{Ba}$ & 802 & 45 & 313 & 296 \\
\hline & $\mathrm{Sr}$ & 252 & 325 & 87 & 116 \\
\hline & $\mathrm{Zr}$ & 199.5 & 288.8 & 72.4 & 66.3 \\
\hline & $\mathrm{Y}$ & 35.3 & 41.7 & 8.2 & 9.8 \\
\hline & $\mathrm{Nb}$ & 21.95 & 3.32 & 7.43 & 2.37 \\
\hline & $\mathrm{Hf}$ & 4.42 & 7.68 & 1.31 & 1.23 \\
\hline & $\mathrm{Ta}$ & 0.9 & 0.3 & 1.3 & 0.3 \\
\hline & Th & 1.7 & 5.2 & 0.9 & 0.5 \\
\hline & Mo & 0.26 & 0.33 & 0.52 & 0.94 \\
\hline & Sn & 3.4 & 2.1 & 1 & 1.1 \\
\hline & $\mathrm{Ga}$ & 17.37 & 18.10 & 19.41 & 18.21 \\
\hline & $\mathrm{Cu}$ & 6.63 & 41.10 & 3.63 & 11.63 \\
\hline & $\mathrm{Zn}$ & 97.7 & 74.5 & 22.4 & 53 \\
\hline & $\begin{array}{c}\mathrm{Ag} \\
(\mathrm{ppb})\end{array}$ & 86 & 91 & 59 & 40 \\
\hline & As & 0.6 & 7.0 & 2 & 0.7 \\
\hline & $\mathrm{Cd}$ & 0.22 & 0.25 & 0.05 & 0.11 \\
\hline & $\mathrm{Sb}$ & 0.07 & 0.43 & 0.07 & 0.03 \\
\hline & $\mathrm{Bi}$ & 0.16 & 0.08 & 0.05 & - \\
\hline & W & 53 & 31.2 & $>200.0$ & 81.6 \\
\hline & $\mathrm{Be}$ & 3 & n.d & 2 & 2 \\
\hline & $\mathrm{Li}$ & 10 & 31.2 & 21.1 & 25.3 \\
\hline & Cs & 2.4 & 0.2 & 1.5 & 0.8 \\
\hline & $\mathrm{U}$ & 0.3 & 1 & 0.2 & 0.1 \\
\hline \multicolumn{2}{|c|}{ Rocks name } & $\overline{~ S y e n i t e ~}$ & $\overline{~ G a b b r o}$ & $\overline{~ S y e n i t e}$ & Syenite \\
\hline
\end{tabular}




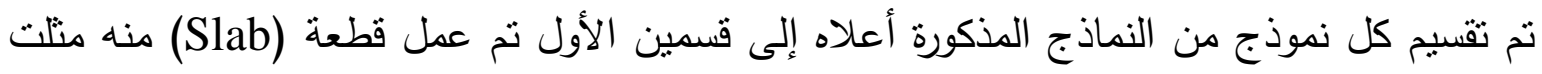

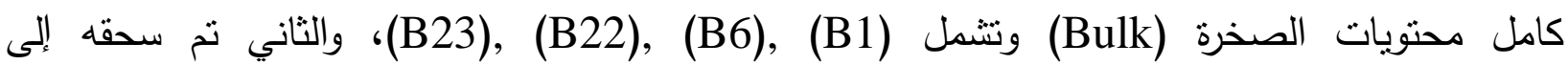

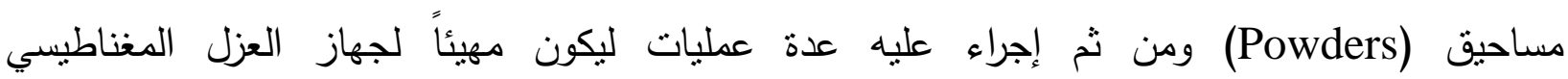
(Fratz Isodynamic Magmatic Separator) علوم الأرض/ جامعة الموصل. إن الغرض من تقسيم كل نموذج من النماذج المنتخبة إلى قسمين يكون المديل

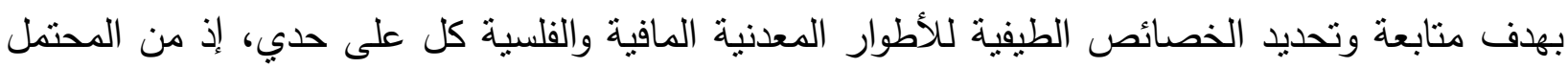
وجود تجمعات معدنية مميزة (مافية أو فلسية) في مواقع اخرى خارج حدود منطقة البحث، و إذا لم يتم تحديد البصمة الطيفية لهذه الأطوار فسوف يتم تجاهل هذه التجمعات المعدنية وبالتالي تجاهل تلاك المواقع (مثال: لوحظ في منطقة البحث وجود تجمعات مافية يزيد حجمها عن المتر). في حين تم تحديد الخصائص الطيفية

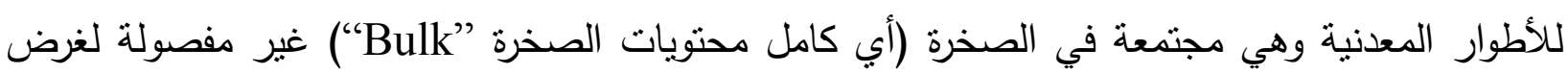

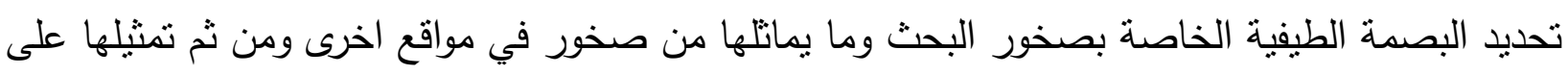
مرئيات فضائية مصححة طيفياً.

خطوات تهيئة النماذج لجهاز العزل المغناطيسي: 1- تكسير النموذج بواسطة الهمر إلى قطع صغيرة، ليسهل سحقة بجهاز السحق (الكسارة الفكية).

2- سحقه بجهاز الكسارة الفكية، و إجراء عملية التربيع والمخروط (Cote and quartering) لتمثيل جميع المكونات المعدنية التي تشكل النموذج الصخري.

3- نخل المساحيق بمنخل ذي حجم (16 mesh).

4- نخل المساحيق ذات الحجم الحبيبي (45 mesh) (16 mesh).

5- غسل المساحيق ذات الحجم الحبيبي (45 mesh) بالماء المقطر لكي يكون حجم الحبيبات المعدنية أكثر تجانساً.

6- تجفيف هذه المساحيق في فرن التجفيف بدرجة حرارة (150 C C لجهاز العزل المغناطيسي. 
تم تصنيف المساحيق الصخرية الناتجة من جهاز العزل المغناطيسي إلى ثلاثة مجاميع الأولى:

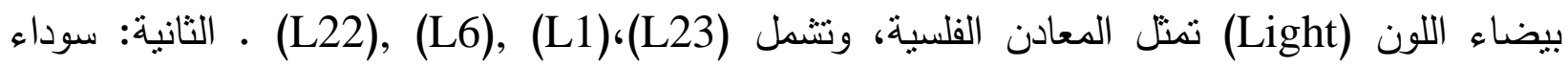

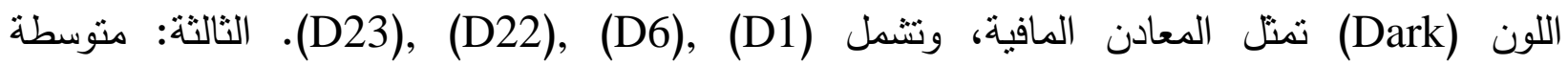

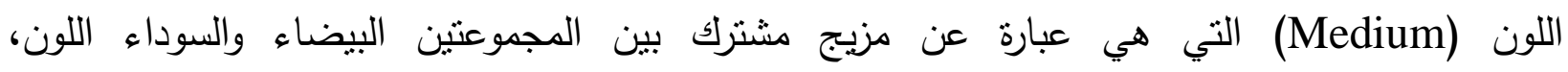
وتتشمل هذه المجموعة المساحيق الصخرية (M23), (M22), (M6), (M1). تم تحليل هذه النماذج

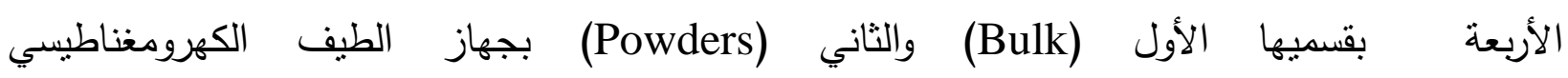
(ASD-Field Spectroradiometer) خصائصها الطيفية وكما مبين في الفقرة القادمة.

\section{تحليل الانعكاسية الطيفية}

يوضح (الثكل 7) منحنيات الانعكاسية الطيفية للنماذج تحت البحث، ويلاحظ في بعض منها وجود

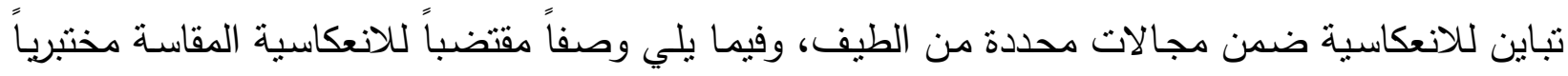

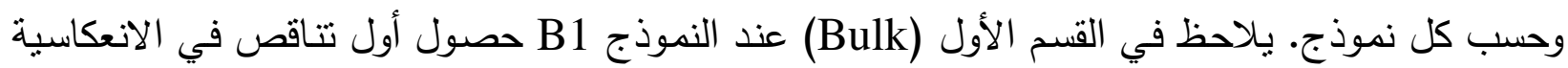

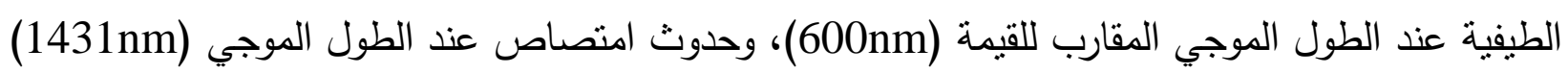

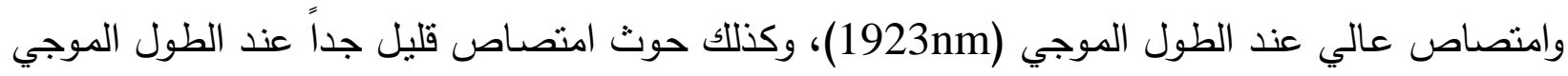

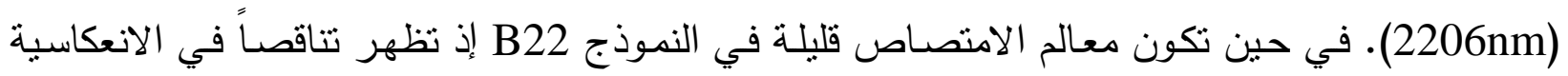
الطيفية مـع زيادة الطول الموجي، كما ويخلو منحني هذا النموذج من أي ارتفاعات أو انخفاضـات حادة.

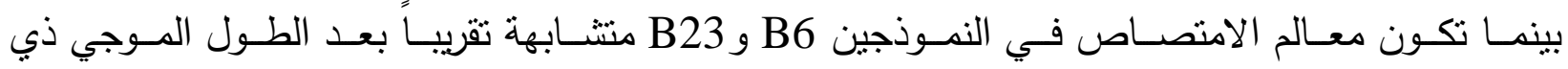

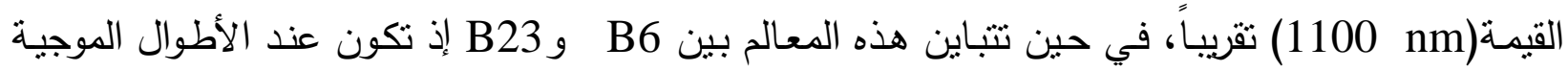

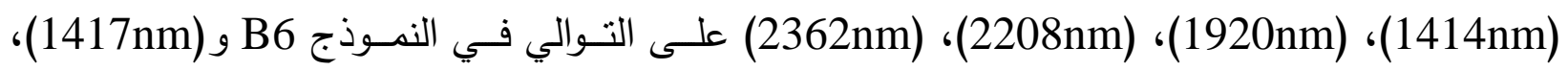

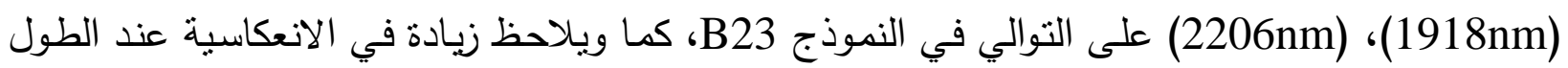
الموجي (1012nm) في النموذج B6، وأن شدة الامتصاص تكون أعلى في B6 مقارنة بالامتصاص ذاته في B23. بشكل عـام إن أفضـل امتصـاص بظهره هذا القسـ (Bulk) يقع بـين الأطسوال الموجيـة فئس .$(1918-1923 \mathrm{~nm})$ 

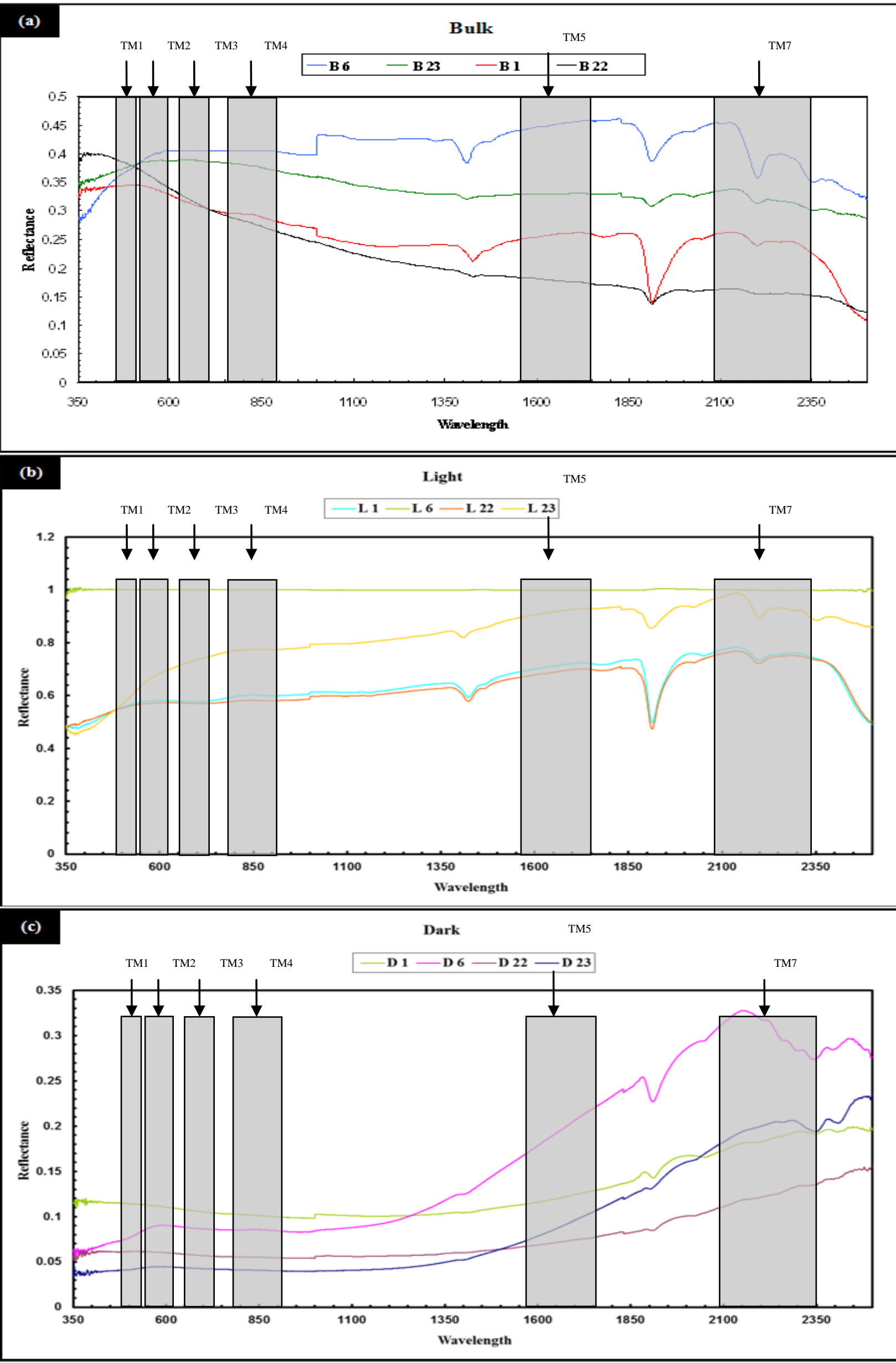

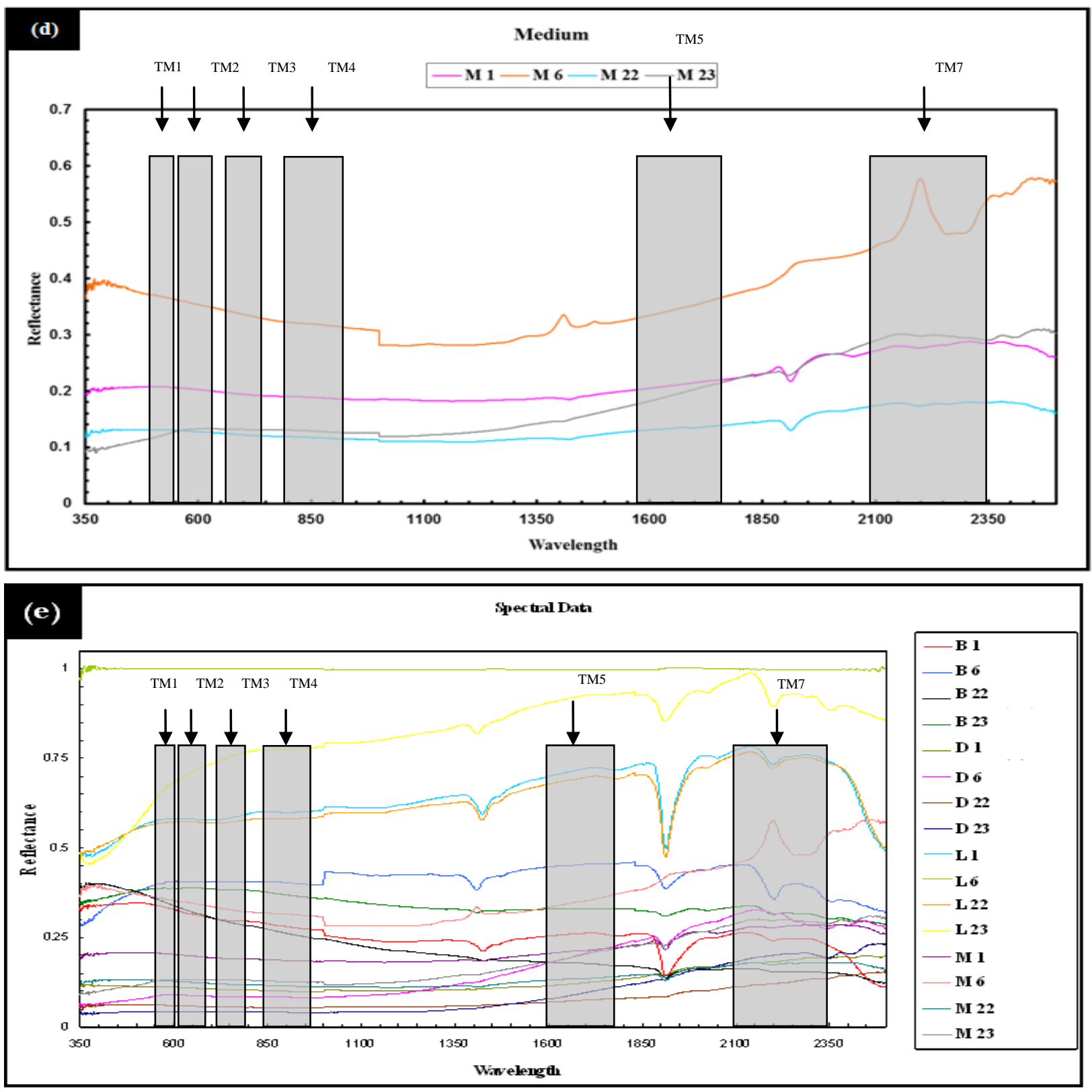

الثكل 7: أثنكال (d), (c), (b), (a) توضح خصائص الانعكاسية الطيفية في المجاميع الأربعة، (e) يوضح تللك الخصائص في كافة العينات.

عند تتبع الخصائص الطيفية في القسم الثاني (Powders)، فيلاحظ في المجموعة الأولى البيضـاء اللون (Light) بأن معالم الامتصاص تكون متشابهة في النموذجين L1 و L22، والتي تكون عند الأطوال

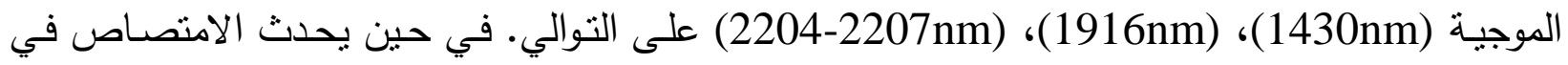


النمـوذج L23 عند الأطـوال الموجيـة (1416nm)، (1917nm)، (2207nm) على التوالي مـع حدوث

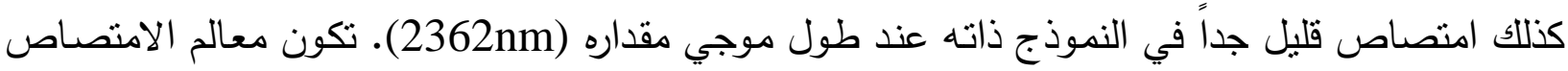

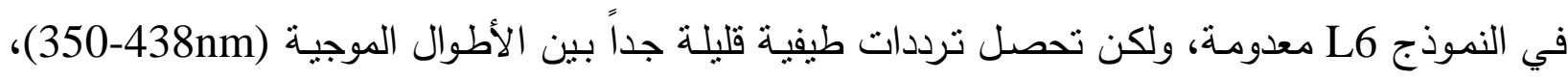

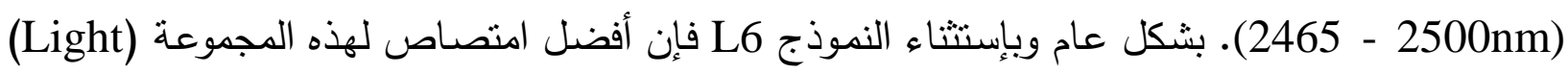
يكون بين الأطوال الموجية (1916-1917nm)، مع زيادة قليلة جداً في الانعكاسية عند طول موجي مقداره .(1012nm)

نظهر الخصائص الطيفية في المجموعة الثانية السوداء اللون (Dark) زيادة قليلة في الانعكاسية تحدث في النموذجين D1 و D6 عند الاطوال الموجية (1894nm) و (1888nm) على التوالي التي يتبعها

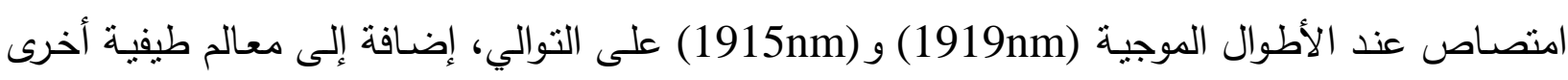

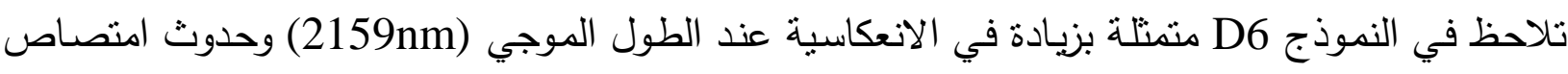

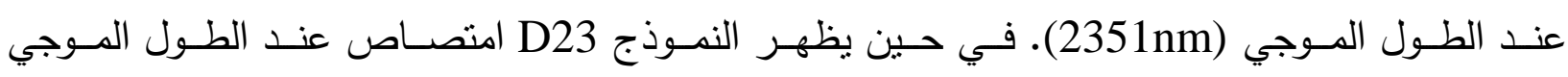

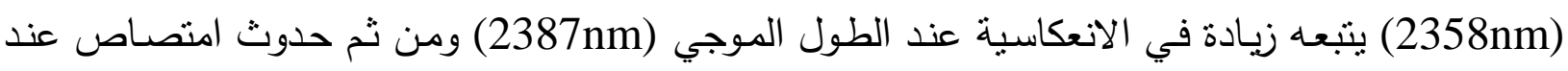

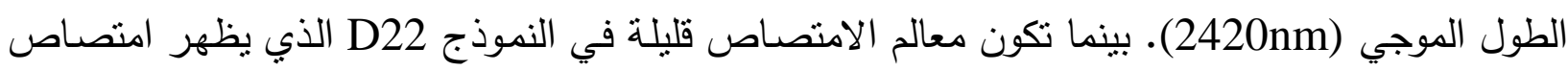

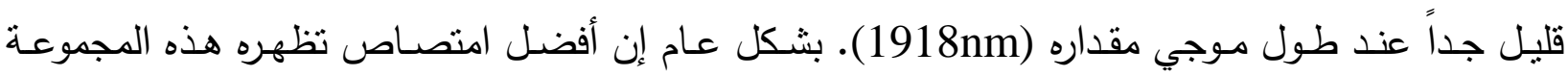

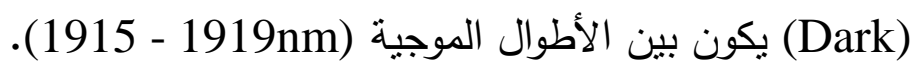
تشير الخصائص الطيفية للمجموعة الثالثة المتوسطة اللون (Medium) إلى الى حدوث زيادة قليلة

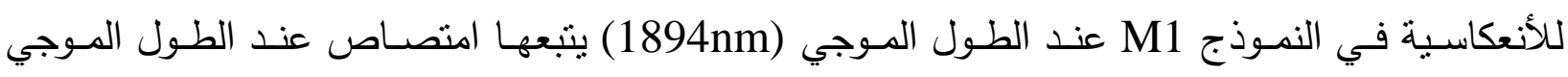

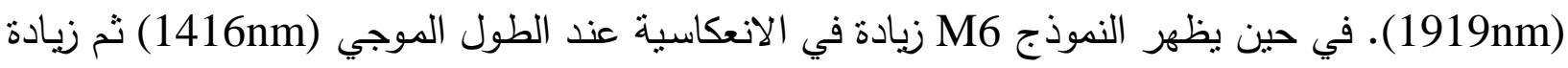
أخرى أكبر الأولى عند طول موجي مقدار (2205nm) والتي يتبعها حدوث امتصاص يقع بين الأطوال

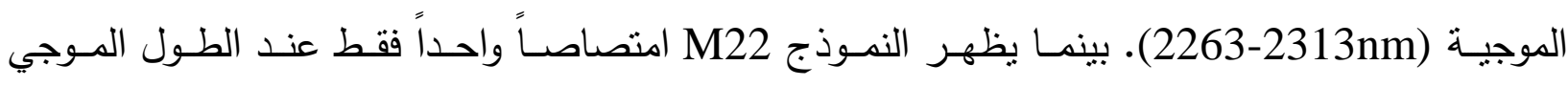
غير واضحة لكن تحدث ترددات طيفية بين الأطوال الموجية (350-405nm). بشكل عام تكون معالم الامتصاص في هذه المجموعة (Medium) قليلة، وإن أفضل امتصاص لوحظ يقع بين الأطوال الموجية (1919-1920nm) و (2363-2313nm). يلاحظ مما ذكر أعلاه وجود تباين في الخصائص الطيفية (الانعكاس والامنصاص) عند أطوال موجية

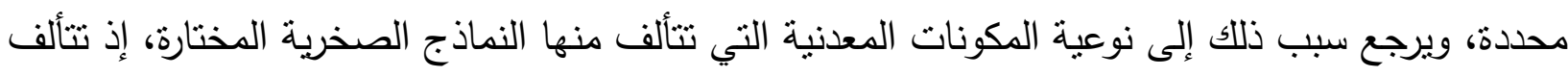

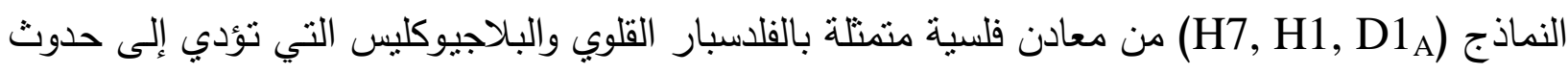

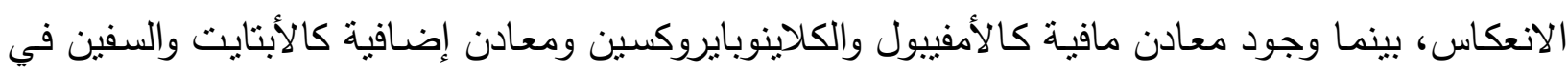

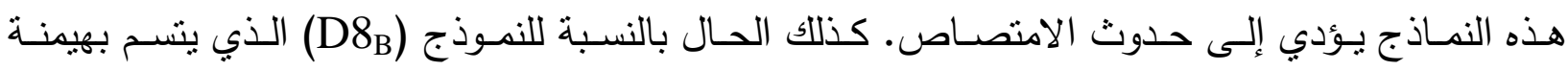

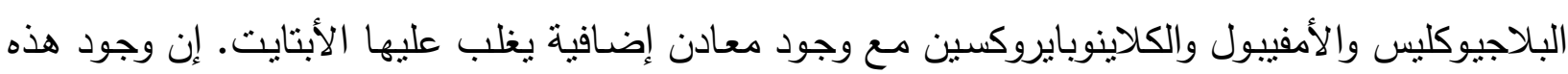


المكونات المعدنية بصورة متتاوبة في الصخور تحت البحث يؤدي إلى حدوث تتاوب في الخصائص الطيفية

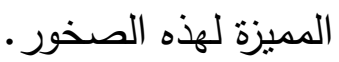

\section{استخدام التصنيف الموجه في تحديد انتثار المقحمات البكمتايتية}

تم استخدام التصـنيف الموجهه في تحديد مواقع المقحمات البكمتايتيـة وانتشـارها في بعض الأنطقة لمنطقة الدراسة والتي كان هناللك صعوبة في الوصول اليها. إن هذا النوع من التصنيف الرقمي يتطلب معرفة مسبقة للمنطقة المطلوب تصنيفها لكي يتم اختبار مواقع عينات ممثلة لنمط معروف من غطاء الاراضي تدعى مناطق التدريب (Training areas) وذلك لوضع دليل تفسير عددي للمصنف المستخدم لكي يقوم بتصنيف الخصائص الطيفية لكل نمط من انماط المعالم المدروسة (Lillesand and Kiefer,1994). تم في الدراسة الحالية الاعتماد على التصنيف الموجه بطريقة التحليل الطيفي للاهداف. إذ تم انتقاء بعضاً من نماذج الدراسة والمبينة في( الثكل 7 ) واستقراء خصائصها الطيفية بواسطة جهاز الطيف الكهرومغناطيسي (ASD-Field Spectroradiometer) وجود وانتشـار هذه الخصائص الطيفية، تم تصحيح المرئية الفضـئية متعددة الاطياف للقمر لاندسات من خلال موديل تصحيح الغلاف الجوي ، إذ نم إجراء هذا النوع من المعالجة من Hypercubes-Flaash atmospheric correction model) خلال برنامج (ENVI 4.7) ليصبح بالامكان استقراء الطول الموجي (Wavelength) لاي وحدة صورية موجودة في المرئية الفضائية ومن ثم تصنيف المرئية الفضائية بالاعتماد على خصائص الانعكاسية الطيفية للنماذج المقاسة مختبرياً (Khan and Jacobson, 2008 ; Swalf et al., 2003)، وفي حالة وجود تشنابه لمنحني الانعكاسية الطيفية لنموذج معين مع وحدة صورية معينة سوف يتم عزل هذه الوحدة واعتبارها مقحم بكمتايتي، أما في حالة عدم وجود تطابق فان هذه الوحدة لن يتم تمثيلها بأية قيمة رقمية وعليه تكون بلون اسود. اعتماداً على خصائص الانعكاسية الطيفية للنماذج المختارة تم تحديد وجود بعضاً من المقحمات البكمتايتية في الجزء الشمالي الغربي من نطاق درز زاكروس (ZSZ) (الشكل 8). يمكن من خلال الشكل ملاحظة وجود تطابق للمقحمات الظاهرة في التصنيف مع النطاق الحقلي الذي تم فيه جمع النماذج، فضلاً عن وجود عدد من الأنطقة الاخرى المنتشرة في مواقع متفرقة من المنطقة. يعد النطاق الواقع إلى الثمال

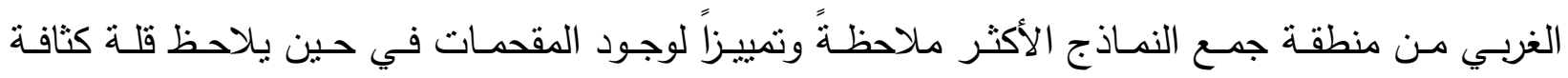
المقحمات في المواقع الاخرى. إن الزيـادة والنقصـان في كثافة المقحمات لايمكن الجزم فيها بشكل قاطع بسبب أن المرئية المستخدمة في الدراسـة الحالية تتصف بقدرة تمييز مكانية (Spatial resolution) قدرها (30×30) متراً. أي أن ابعاد اي هدف ارضي يقل عن هذا المقدار (اي 30×30 مترا) لا يمكن كثفه من

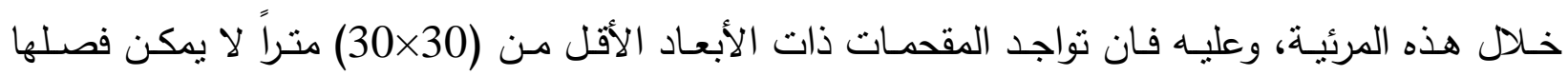


والتعرف عليها ويتطلب للكثف عنها الاعتماد على مرئيات فضائية تتميز بكونها ذات قدرات تمييزية مكانية

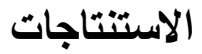

1- إن تحضير النماذج مختبرياً لغرض قياس الانعكاسية الطيفية للمقحمات البكمتايتية يعد نموذجاً مهماً

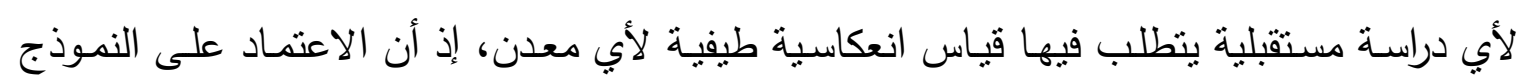
بهيئة حجمية (Bulk) وبهيئة مسحوق (Powder) يكون مناسباً لاستغلال جميع المعادن المكونة للصخرة في استخلاص البصمة الطيفية منها.

2- إن الاعتماد على طريقة التصنيف الموجه بدلالة البصمة الطيفية يعطي نتائج جيدة في التحري عن الكتل الصخارية في مناطق يتعذر الوصول اليها وهذا ما توضح جلياً في الدراسة الحالية من خلال التعرف على بعض المناطق ذات المحتوى البكمنايتي.

3- إن استخدام المرئيـات الفضـائية المصـحمة طيفياً يكون عـاملاً مكـلاً للقيـاس المختبري الخـاص بالبصمة الطيفية للأهداف الأرضية. ولكن يجب مراعاة حجم الهدف ودقة تمييز المرئية الفضائية. اذ نم ملاحظة وجود بعض التقصير نتيجة دقة التمييز المكانية للمرئية الفضائية المستخدمة والعائدة للقمر لاندسات (30×30 مترا)، ويمكن تجاوز هذا القصور في دقة التمييز عند اجراء دراسـات مستقبلية من خلال استخدام مرئيات ذات دقة تمييز اعلى كمرئيات القمر ايكونوس (Ikonos) او هوني كويك بيرد (Quick Bird). 


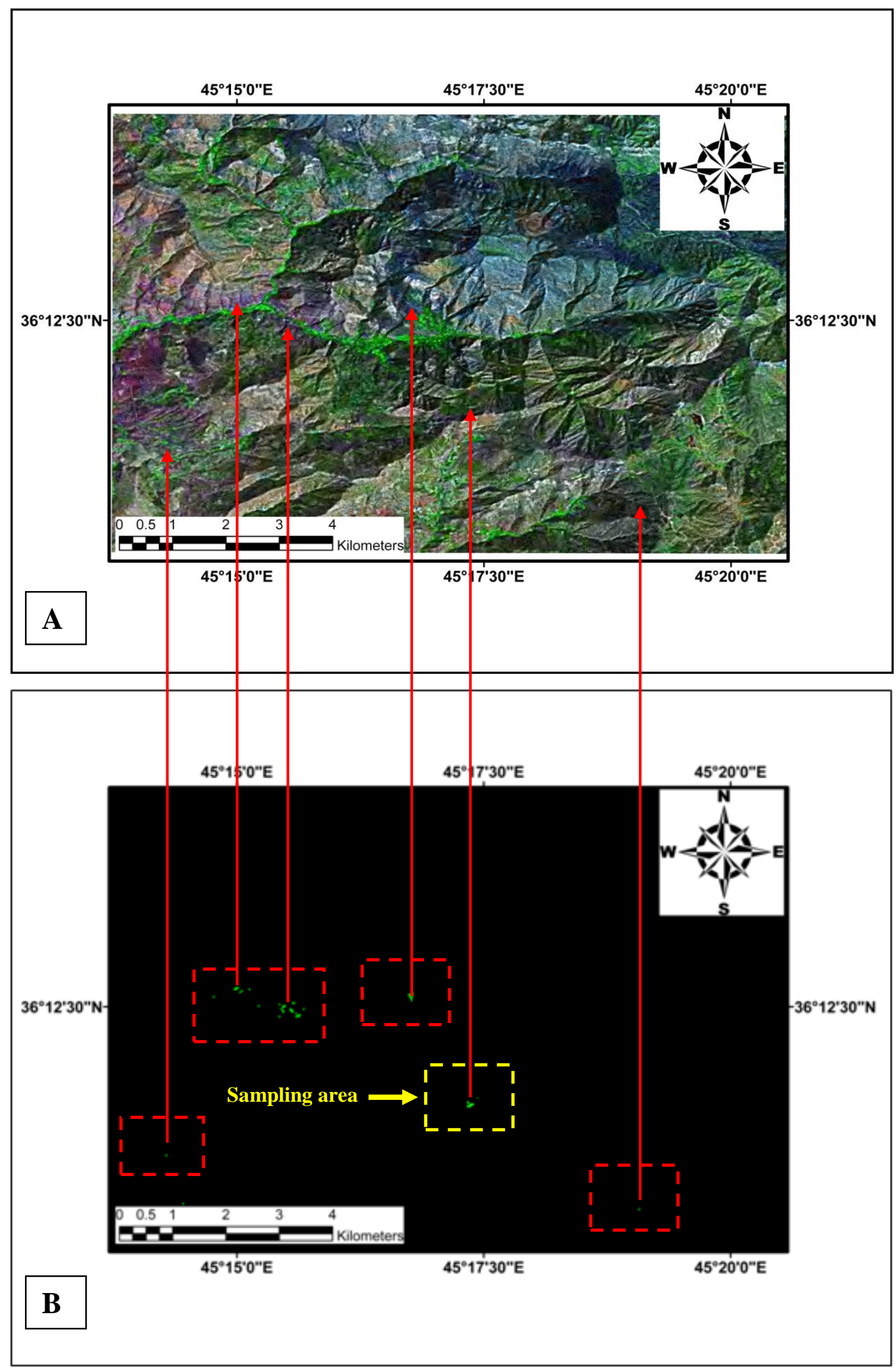

الشكل 8: (A) المرئية الفضائية الملونة، (B) المرئية الفضائية المصنفة

(النقاط الخضراء تمنل مواقع المقحمات البكمنايتية). 


\section{REFERENCES}

Aswad, K. J., 1999. Arc-Continental Collision in Northeastern Iraq as

Evidence by the Mawat and Penjwen Ophiolite Complex. Raf. Jour. Sci.,

Vol. 10, pp. 51 - 61.

Aswad, K. J. A., Aziz, N. R. H., and Koyi, H. A., 2011. Cr-spinel Compositions in

Serpentinites and their Implications for the Petrotectonic History of Zagros

Suture Zone, Kurdistan Region, Iraq. Geological Magazine., pp. 1 - 17.

Buday, T., and Suk, M., 1978. Report on the Geological Survey in NE Iraq between Halabja and Qala-Diza, Unpubl. Report, NIMCO Lib., Baghdad.

Buday, T., and Jassim, S. Z., 1987. The Regional Geology of Iraq, Vol. 2, Tectonism, Magmatism and Metamorphism (eds.) Kassab, I. M. and Abass,

M. J., Geological Survey and Mineral Investigation, Baghdad, Iraq., 352 p.

Jassim, S. Z., Buda, G., Neuzilova, M., and Suk, M., 1982a. Metamporphic

Development of the Iraqi Zagros Ophiolitic Zone. Academia publishing house of the Czechoslovak Academy of Science, Krystalinikum, Vol. 16, pp. $21-40$.

Jassim, S. Z., and Buday, T., 2006. Units of the Unstable Shelf and the Zagros Suture. In: S. Z. Jassim and J. C. Goff (eds), Geology of Iraq.

Dolin, Prague and Moravian Museum, Brno, pp. 71-83.

Jassim, S. Z., Buday, T., Cicha, I., and Opletal, M., 2006a.Tectonostratigraphy of the Zagros Suture. In: S. Z. Jassim and J. C. Goff (eds), Geology of Iraq. Dolin, Prague and Moravian Museum, Brno, pp. 199 - 211.

Jassim, S.Z., Suk, M., and Waldhausrova, J., 2006b. Magmatisim and metamorphism in the Zagros Suture. In: S. Z. Jassim and J. C. Goff

(eds), Geology of Iraq. Dolin, Prague and Moravian Museum, Brno, pp. $212-231$.

Jassim, S. Z., Waldhausrova, J., and Suk, M., 1982b. Evolution of Magmatic activity in Iraqi Zagros Complexes. Academia publishing house of the Czechoslovak Academy of Science, Krystalinikum, Vol. 16, P. 87 - 108.

Khan, S. D., and Jacobson, S., 2008. Remote Sensing and Geochemistry for Detecting Hydrocarbon Microseepages. GSA Bulletin, Vol. 120, No. 1/2, pp. 96 - 105.

Lillesand, T. M., and Kiefer, R. W., 1994. Remote Ssensing and Image Iinterpretation, 3 nd Ed. John Willey and Sons incop., New York, 721p.

Schneiderhohn, H., 1961. Die Erzlagerstatten der Erde - Band II: Die Pegmatite. Gustav Fischer Verlag, Stuttgart, Germany, 720 p.

Streckeisen, A., 1976. To each plutonic rock its proper name. Earth Science Reviews, Vol. 12, pp. 1 - 33.

Swalf , P., Crosta, A., and Filho, S., 2003. Remote sensing Signature of the morro do ouro gold Deposit, Minas Gerais, Brazil, using Reflectance Spectrometry: Application to Mineral Exploration using Spaceborne Multispectral Sensors, Revista Brasileira de Geociências. Vol. 33, pp. 221 - 227. 